\title{
Maternal nutritional status, a sine qua non condition for fetal, neonatal, child's and adult's outcome
}

\author{
Cosmin Rugina ${ }^{1}$, Cristina Oana Marginean ${ }^{2}$, Lorena Elena Melit ${ }^{2}$, Claudiu Marginean ${ }^{1}$ \\ ${ }^{1}$ Department of Obstetrics and Gynecology, "George Emil Palade" University of Medicine, Pharmacy, \\ Sciences and Technology, Tg. Mures, Romania \\ ${ }^{2}$ Department of Pediatrics I, "George Emil Palade" University of Medicine, Pharmacy, Sciences and \\ Technology, Tg. Mures, Romania
}

\begin{abstract}
Excessive gestational weight gain is a predictive factor for maternal obesity, with implications on newborn's weight and potential short- and long-term complications. Gestational weight gain depends on ethnic and social factors, as well as on parity. Excepting the aforementioned factors, we must also recall the major impact of the genetic susceptibility being pointed out that three essential periods influence fetal evolution, i.e. periconceptional, intrauterine and postnatal. The intrauterine environment owns an essential role in the optimal development of fetus with an effect on the offspring's organ structure and functions, being currently assumed that adulthood pathologies originate in the perinatal period. Thus, the relationship between excessive gestational weight gain and child's obesity or metabolic disorders is well documented. Moreover, recent information from the literature suggests that child's allergies, wheezing or asthma might also be related to maternal nutritional status.

To sum up, excessive gestational weight gain owns a decisive role in the development of child's obesity and metabolic disorders imposing the major importance of a balanced diet during pregnancy in order to favor an optimal weight gain with a positive effect on fetal wellbeing that will further prevent the offspring's metabolic risk.
\end{abstract}

Keywords: gestational weight gain, maternal obesity, newborn's weight

\section{INTRODUCTION}

Obesity represents a major public health problem, a flagella of the $21^{\text {st }}$ century, with multiple short- and long-term implications. Excessive gestational weight gain is a predictive factor for postpartum maternal obesity with implications on fetus (possible fetal macrosomia) and birth weight, involving short- and medium-term complications such as childhood obesity and cerebral palsy, or long-term ones like stroke, coronary disorders, obesity and asthma (1). Rooney et al. revealed that the predictive factors for postpartum obesity include an excessive gestational weight gain and the incapacity to lose the gained weight within the next 6 month after birth (2).

The Institute of Medicine (IOM) recommends different ranges for gestational weight gain in the setting of monofetal pregnancy depending on the pre- conceptional body mass index (BMI). Thus, for a normal preconceptional BMI $\left(18.5-24.9 \mathrm{~kg} / \mathrm{m}^{2}\right)$, a weight gain between 11.5 and $16 \mathrm{~kg}$ is recommended for minimalizing the complications (3). Contrariwise, in pregnant women with a higher preconceptional BMI, the gestational weight gain is reversely related to this BMI: for a BMI $<18.5 \mathrm{~kg} / \mathrm{m}^{2}$, the recommended gestational weight gain ranges between 12.5 and $18 \mathrm{~kg}$, for overweight women, with a BMI between 25 and $29.9 \mathrm{~kg} / \mathrm{m}^{2}$, it is recommended to gain between 7 and $11.5 \mathrm{~kg}$ during pregnancy, while for obese women, with a BMI $>30 \mathrm{~kg} / \mathrm{m}^{2}$, the weight gain shuld vary between 5 and $9 \mathrm{~kg}$. In the setting of multiple pregnancy and a normal BMI, the weight gain should be $17-25 \mathrm{~kg}$, in overweight women 14-23 $\mathrm{kg}$, while in obese 11-19 $\mathrm{kg}$ (4). A metanalysis which assessed the impact of the complications related to excessive gestational weight gain on pregnancy and 
ofspring pointed out an association of LGA newborns, arterial hypertension or preeclampsia, and if it occurs within the first 20 gestational weeks increases the risk for gestational diabetes (5).

\section{RISK FACTORS FOR MATERNAL OBESITY}

It is well documented that gestational weight gain is closely related to maternal morbidity. Therefore, a study performed on 2.4 million of pregnant women for USA concluded that only $31 \%$ had an appropriate weight gain according to the IOM, while almost 50\% had a weight gain above the normal limits (6). The gestational weight gain depends on ethnic and social factors, as well as on parity. Thus, pregnant women without superior education, without a life partner, and multipara women usually have an poor gestational weight gain (7). The study of Zhang et al. pointed out that social and economical factors have a great impact on the both fetal prognosis at birth and postpartum proving that newborns from mother with a poor educational or economic level, smokers or with inappropriate nutritional status, are commonly found with a worse outcome (8). Contrariwise, in a study of Neves et al., education was also related to maternal obesity being pointed out that $58.3 \%$ of the pregnant women with 8 years of education were obese, while only $36.6 \%$ of those with 12 years of education were obese (9). Moreover, emesis gravidarum within the 1 st trimester of pregnancy is frequently associated to a weight deficit during pregnancy, failing in reaching the optimal weight until the end of the pregnancy according to the study of Meinich et al. (10). The weight gain during the first trimester is essential for fetal wellbeing and its weight, being considered that birth weight is related to the weight gain within the first half of gestation (11). Nevertheless, Karachaliou et al. consider that weight gained during the 2 nd and the 3rd trimesters is more important (12). It seems that emesis gravidarum in the $1^{\text {st }}$ trimester can be associated also with excessive gestational weight gain (13).

Age is another decisive factor for gestational weight gain. Thus, Stuebe et al. proved that pregnant women above the age of 35 had a lower weight gain when compared to those between 20-35 years of age (13).

Ethnical differences were also proved to influence pregnancy outcomes and fetal prognosis. Madzia et al. noticed that blacks express a greater risk for poor weight deficit and preterm labor in comparison to white people (14). Similarly, Fontaine et al. concluded that black pregnant women had a diminished weight gain during all trimesters of pregnancy, excepting underweight pregnant women before preg- nancy (15). Kinnunen et al. noticed a greater weight gain at 28 gestational weeks in East-European pregnant women when compared to West-European ones, as well as compared to those from Middle Orient. The authors pointed out also that Caucasian pregnant women gad the greatest fat deposits (16).

Parity is corelated with preconceptional BMI according to the study of Paulino et al. who proved that in multipara pregnant women obesity has almost a double incidence versus primipara, albeit gestational weight gain seems to be unrelated with pregnant woman's pregnancy number (17). Similar findings were revealed by the metanalysis of Hill et al., who concluded that multipara have an increased precoceptional when compared to nullipara (18). The study of Fraser et al. aimed to assess the resting weight gain by evaluating certain parameters such as BMI, waist circumference and blood pressure in women after 16 years from the time of birth. The authors proved that pregnant women with a gestational weight gain below the recommendations of the IOM had a BMI and a waist circumference smaller that those with excessive gestational weight gain (19).

Gestational diabetes mellitus, defined as diabetes mellitus diagnosed during the 2 nd or the 3rd trimester of pregnancy in a pregnant women without prior history, represents one of the main gestational pathologies associated with an excessive gestational weight gain (20). A genetic study performed by Zhang et al. identified several genes that increase the risk for gestational diabetes mellitus, among which 6 are related to insulin secretion and one to insulin resistance (21).

Smoking during pregnancy is associated with a lower weight gain being proved that pregnant women who give up smoking during pregnancy or closely before conception present a greater weight gain when compared to those who continue to smoke (22). Moreover, the newborns from smoker mothers will not only have a lower birth weight, but also smaller head circumference and femur length starting with the second trimester of pregnancy (23). Thus, it was stated that for a multipara smoker a weight gain between $16-19 \mathrm{~kg}$ is required for maintaining the same risk of SGA versus 5-9 $\mathrm{kg}$ for a non-smoking multipara pregnant woman, fact that will definitely promote the remaining postpartum weight gain (4). Nevertheless, Poon et al. pointed out that independently of the energy intake during pregnancy, smoking pregnant women had more commonly SGA fetuses, concluding that gestational weight gain and energy intake are not the only factors that influence birth weight (24).

Excepting the aforementioned factors, we must also recall the major impact of the genetic suscepti- 
bility being pointed out that three essential periods influence fetal evolution, i.e. periconceptional, intrauterine and postnatal (25). In addition, Yajnik et al. consider that gametogenesis, embryogenesis and placental formation represent essential stages for the prevention of offspring's risks (26).

According to Lagadec et al., the favorable factors that influence the quality of the pregnant woman, with benefits on maternal and fetal wellbeing are represented by a proper socio-economic level, primiparity, exercise during pregnancy, whereas obesity, emesis gravidarum, in vitro fertilization, complications before or during pregnancy account for negative factors (27).

\section{THE IMPACT OF PREGNANT WOMAN'S NUTRITIONAL STATUS ON NEWBORN}

The intrauterine environment owns an essential role in the optimal development of fetus with an effect on the offspring's organ structure and functions, being currently assumed that adulthood pathologies originate in the perinatal period (28). It is well-known that pregnant woman's nutrition impact the fetus. Thus, the study of Williams et al. proved that maternal BMI, her weight gain and life style represent risk factors for offspring's obesity, either immediately postpartum by macrosomia, or by increasing the risk for infantil obesity and the incidence of diabetes mellitus (29). Therefore, excessive gestational weight gain owns a decisive role in the development of obesity and metabolic disorders during childhood, imposing the urgent need for a balanced diet during pregnancy in order to favor an optimal weight gain with a positive effect on fetal wellbeing that will prevent the offspring's metabolic risk. Both SGA and LGA fetuses associate increased morbidity risks with a higher risk for type 2 diabetes mellitus in SGA fetuses and overweight and obesity in LGA (30). Godfrey et al. concluded that maternal obesity is correlated with the development of cardiovascular disorders and stroke during adulthood and asthma during childhood (1) Moreover, it was noticed that

Conflict of interest: none declared

Financial support: none declared

\section{REFERENCES}

1. Godfrey KM, Reynolds RM, Prescott SL, Nyirenda M, Jaddoe VWV, Eriksson JG, et al. Influence of maternal obesity on the long-term health of offspring. Lancet Diabetes Endocrinol. 2017 Jan;5(1):53-64.

2. Rooney BL, Schauberger CW. Excess pregnancy weight gain and long-term obesity: one decade later. Obstet Gynecol. 2002 Aug;100(2):245-52.

3. Most J, Dervis S, Haman F, Adamo KB, Redman LM. Energy Intake Requirements in Pregnancy. Nutrients. 2019 Aug 6;11(8).

4. Institute of Medicine (US) and National Research Council (US) Committee to Reexamine IOM Pregnancy Weight Guidelines. Weight Gain During preconceptional weigh loss in obese women might decrease the risk of obesity (31).

The study of Mina et al. proved that cortisol levels in children who come from obese mothers, with a suboptimal level of HDLc, are higher (32). Neurological and psychological disorders, as well as social insertion problems are not to be neglected in obese patients. Thus, a study that followed the neuro-psychic effects in children that originate from obese mothers, found that these children are more predisposed to developing an aggressive behavior, sleep disorders and signs of attention deficit and hyperactivity disorder (ADHD) (33).

Another worth mentioning hypothesis is the implication of maternal obesity in child's allergies. Thus, Forno et al., in a metanalysis that included 14 studies, concluded that asthma and wheezing are more frequent in children with obese mothers (34). Similarly, Chen et al. correlated child's allergies with maternal BMI and gestationa weight gain, pointing out that an increased frequency of wheezing, asthma, allergic rhinitis and eczema as a consequence of excessive gestational weight gain, but without identifying any correlation between preconceptional BMI and child's allergies (35). Druker et al. also performed a study on a representative sample of pregnant women and children with atopic dermatitis and noticed that the latter one is associate with gestational weight gain, without being influenced by preconceptional BMI (36). Contrariwise, the study of Harpsoe et al. found no connection between gestational weight gain and atopic dermatitis (37).

\section{CONCLUSIONS}

Gestational weight gain owns a major role in the development of different conditions during childhood. Thus, maternal weigh might have a dichotomous role, assuring the fetal and neonatal wellbeing, or contrariwise an inappropriate maternal nutritional status will negative impact the offspring's intrauterine development, but also future short- and longterm complication in child.
Pregnancy: Reexamining the Guidelines. Rasmussen KM, Yaktine AL, editors. Washington (DC): National Academies Press (US); 2009.

5. Santos S, Voerman E, Amiano P, Barros H, Beilin LJ, Bergström A, et al. Impact of maternal body mass index and gestational weight gain on pregnancy complications: an individual participant data metaanalysis of European, North American and Australian cohorts. BJOG. 2019 Jul;126(8):984-95.

6. Leonard SA, Abrams B, Main EK, Lyell DJ, Carmichael SL. Weight gain during pregnancy and the risk of severe maternal morbidity by prepregnancy BMI. Am J Clin Nutr. 2020 Apr 1;111(4):845-53. 
7. Hickey CA. Sociocultural and behavioral influences on weight gain during pregnancy. Am J Clin Nutr. 2000 May;71(5 Suppl):1364S-70S.

8. Zhang P, Wu J, Xun N. Role of Maternal Nutrition in the Health Outcomes of Mothers and Their Children: A Retrospective Analysis. Med Sci Monit. 2019 Jun 14;25:4430-7.

9. Neves AG, Kasawara KT, Godoy-Miranda AC, Oshika FH, Chaim EA, Surita FG. Early menarche and teenager pregnancy as risk factors for morbid obesity among reproductive-age women: A case-control study. Clinics (Sao Paulo). 2017 Oct;72(9):547-53.

10. Meinich T, Trovik J. Early maternal weight gain as a risk factor for SGA in pregnancies with hyperemesis gravidarum: a 15-year hospital cohort study. BMC Pregnancy Childbirth. 2020 Apr 28;20(1):255.

11. Retnakaran R, Wen SW, Tan H, Zhou S, Ye C, Shen M, et al. Association of Timing of Weight Gain in Pregnancy With Infant Birth Weight. JAMA Pediatr. 2018 Feb 1;172(2):136-42.

12. Karachaliou M, Georgiou V, Roumeliotaki T, Chalkiadaki G, Daraki V, Koinaki S, et al. Association of trimester-specific gestational weight gain with fetal growth, offspring obesity, and cardiometabolic traits in early childhood. Am J Obstet Gynecol. 2015 Apr;212(4):502.e1-14.

13. Stuebe AM, Oken E, Gillman MW. Associations of diet and physical activity during pregnancy with risk for excessive gestational weight gain. Am J Obstet Gynecol. 2009 Jul;201(1):58.e1-8.

14. Madzia J, McKinney D, Kelly E, DeFranco E. Influence of Gestational Weight Gain on the Risk of Preterm Birth for Underweight Women Living in Food Deserts. Am J Perinatol. 2020 Mar 4.

15. Fontaine PL, Hellerstedt WL, Dayman CE, Wall MM, Sherwood NE. Evaluating body mass index-specific trimester weight gain recommendations: differences between black and white women. J Midwifery Womens Health. 2012 Aug;57(4):327-35.

16. Kinnunen TI, Waage CW, Sommer C, Sletner L, Raitanen J, Jenum AK. Ethnic Differences in Gestational Weight Gain: A PopulationBased Cohort Study in Norway. Matern Child Health J. 2016 Jul;20(7):1485-96.

17. Paulino DS de M, Surita FG, Peres GB, do Nascimento SL, Morais SS. Association between parity, pre-pregnancy body mass index and gestational weight gain. J Matern Fetal Neonatal Med. 2016 Mar;29(6):880-4.

18. Hill B, Bergmeier H, McPhie S, Fuller-Tyszkiewicz M, Teede $H$, Forster $\mathrm{D}$, et al. Is parity a risk factor for excessive weight gain during pregnancy and postpartum weight retention? A systematic review and meta-analysis. Obes Rev. 2017 Jul;18(7):755-64.

19. Fraser A, Tilling K, Macdonald-Wallis C, Hughes R, Sattar N, Nelson $\mathrm{SM}$, et al. Associations of gestational weight gain with maternal body mass index, waist circumference, and blood pressure measured $16 \mathrm{y}$ after pregnancy: the Avon Longitudinal Study of Parents and Children (ALSPAC). Am J Clin Nutr. 2011 Jun;93(6):1285-92.

20. American Diabetes Association. 2. Classification and Diagnosis of Diabetes: Standards of Medical Care in Diabetes-2019. Diabetes Care. 2019 Jan;42(Suppl 1):S13-28.

21. Zhang C, Bao W, Rong Y, Yang H, Bowers K, Yeung E, et al. Genetic variants and the risk of gestational diabetes mellitus: a systematic review. Hum Reprod Update. 2013 Aug;19(4):376-90.

22. Rockhill KM, England LJ, Tong VT, Sharma AJ. Biochemically confirmed smoking cessation and gestational weight gain. Birth. 2019 Jun;46(2):326-34.
23. Abraham M, Alramadhan S, Iniguez C, Duijts L, Jaddoe VWV, Den Dekker HT, et al. A systematic review of maternal smoking during pregnancy and fetal measurements with meta-analysis. PLoS One. 2017;12(2):e0170946.

24. Poon AK, Yeung E, Boghossian N, Albert PS, Zhang C. Maternal Dietary Patterns during Third Trimester in Association with Birthweight Characteristics and Early Infant Growth. Scientifica (Cairo). 2013;2013:786409.

25. Franzago M, Fraticelli F, Stuppia L, Vitacolonna E. Nutrigenetics, epigenetics and gestational diabetes: consequences in mother and child. Epigenetics. 2019 Mar;14(3):215-35.

26. Yajnik CS. Transmission of obesity-adiposity and related disorders from the mother to the baby. Ann Nutr Metab. 2014;64 Suppl 1:8-17.

27. Lagadec N, Steinecker M, Kapassi A, Magnier AM, Chastang J, Robert $\mathrm{S}$, et al. Factors influencing the quality of life of pregnant women: a systematic review. BMC Pregnancy Childbirth. 2018 Nov 23;18(1):455.

28. Simeoni U, Armengaud JB, Siddeek B, Tolsa JF. Perinatal Origins of Adult Disease. Neonatology. 2018;113(4):393-9.

29. Williams CB, Mackenzie KC, Gahagan S. The effect of maternal obesity on the offspring. Clin Obstet Gynecol. 2014 Sep; 57(3):508-15.

30. Cnattingius S, Villamor E, Lagerros YT, Wikström A-K, Granath F. High birth weight and obesity - a vicious circle across generations. Int J Obes (Lond). 2012 Oct;36(10):1320-4.

31. Smith J, Cianflone K, Biron S, Hould FS, Lebel S, Marceau S, et al. Effects of maternal surgical weight loss in mothers on intergenerational transmission of obesity. J Clin Endocrinol Metab. 2009 Nov;94(11):4275-83.

32. Mina TH, Lahti M, Drake AJ, Forbes S, Denison FC, Räikkönen K, et al. Maternal lipids in pregnancy are associated with increased offspring cortisol reactivity in childhood. Psychoneuroendocrinology. 2017 Sep;83:79-83.

33. Mina TH, Lahti M, Drake AJ, Räikkönen K, Minnis H, Denison FC, et al. Prenatal exposure to very severe maternal obesity is associated with adverse neuropsychiatric outcomes in children. Psychol Med. 2017 Jan;47(2):353-62.

34. Forno E, Young OM, Kumar R, Simhan H, Celedón JC. Maternal obesity in pregnancy, gestational weight gain, and risk of childhood asthma. Pediatrics. 2014 Aug;134(2):e535-546.

35. Chen Y, Zhu J, Lyu J, Xia Y, Ying Y, Hu Y, et al. Association of Maternal Prepregnancy Weight and Gestational Weight Gain With Children's Allergic Diseases. JAMA Netw Open. 2020 Sep 1;3(9):e2015643.

36. Drucker AM, Pope El, Field AE, Qureshi AA, Dumas O, Camargo CA. Association Between Maternal Pre-Pregnancy Body Mass Index, Gestational Weight Gain, and Offspring Atopic Dermatitis: A Prospective Cohort Study. J Allergy Clin Immunol Pract. 2019 Jan;7(1):96-102.e2

37. Harpsøe MC, Basit S, Bager P, Wohlfahrt J, Benn CS, Nøhr EA, et al. Maternal obesity, gestational weight gain, and risk of asthma and atopic disease in offspring: a study within the Danish National Birth Cohort. J Allergy Clin Immunol. 2013 Apr;131(4):1033-40. 